\section{Treatment of Syphilis}

Q.-The wife of a G.P.I. has a strongly positive Wassermann reaction but no clinical signs of syphilitic infection. How should she be treated?

A. - With the somewhat meagre details available this question is difficult to answer. We should like to know the age of the patient and her obstetrical history, whether she is past the child-bearing age, and whether there have been any miscarriages. Assuming that the patient is syphilitic but has no cardiovascular lesion and has passed the menopause, everything depends on the state of her cerebrospinal fluid. If this is completely negative (Wassermann, cells, protein, and colloidal gold reaction) it seems doubtful if any treatment is necessary. As an insurance one or two courses of bismuth each year for a few years might be worth while, each course to consist of ten weekly injections of $0.25 \mathrm{~g}$. of an insoluble salt. On the other hand if the fluid is positive, and more particularly if the pathological changes are well marked, active treatment is indicated without delay. This should consist of penicillin and fever therapypreferably artificially induced malaria. At least 4 million units of penicillin should be given by intramuscular injection, either in doses of 40,000 units three-hourly or in doses of 300,000 units twice daily; the malaria should be induced by injection of infected blood and about twelve paroxysms allowed before it is terminated. The follow-up should include examination of the cerebrospinal fluid every six months.

\section{Chemotherapy and Appendicitis}

Q. - Now that we have unlimited penicillin and a large range of sulphonamides, what is considered the best treatment for acute Derforated appendicitis and general peritonitis? Should penicillin be given, and which sulphonamide is advised in what dosage (assuming operation has been carried out)?

A.- The answer to this question is implicit in the bracketed phrase at the end of the paragraph. The treatment of acute perforated appendicitis and general peritonitis is still the operation of appendicectomy, followed by nasal suction drainage of the upper alimentary tract and adequate fluid and salt replacement by the intravenous route. Penicillin and sulphonamides have added to this management only in slight degree. The systematic administration of penicillin will prevent certain of the pulmonary complications of peritonitis and will control any septicaemic manifestations. This is true even when the dominant peritoneal organism is penicillin-resistant, for the metastatic lesions in the chest may well be due to a secondary and penicillin-sensitive infection. Penicillin given systematically does not appear in great concentration in the peritoneal cavity, and if given locally it will be inactivated by the penicillinresistant coliform organisms which complicate peritonitis in its later stages. The soluble sulphonamides may be given by way of the intravenous drip; it has not been clearly shown that the local application of sulphonamides to the peritoneum at the time of operation reduces the mortality significantly. Str. raecalis is highly resistant to penicillin, and for bacterial stasis of this organism the concentration of penicillin required is difficult to obtain in the peritoneal cavity.

\section{Ultraviolet Irradiation Without Goggles}

Q.-Can a carbon arc sunlight lamp be used with safety at say $2 \mathrm{ft}$. $(60 \mathrm{~cm}$.) from the face, for five to ten minutes on alternate days. without protective goggles, provided the eyelids are kept closed?

A.- If the "carbon arc sunlight lamp" in question does not produce more than a first-degree reaction on the face under the stated conditions, there is no need to wear goggles provided the eyes are kept shut. There always exists the possibility of producing - with the same dosage-a second-degree reaction of the more delicate skin of the eyelids. The resulting discomfort and oedema of the loose tissues are easily avoided by smearing the eyelids with cold cream or zinc oxide ointment before irradiation.

Incidentally, it is more effective and more aesthetic to treat the face in two halves with the lamp not directly in front of the patient but over to one side. This can be achieved by making the patient face the lamp and then turn the head through $45^{\circ}$ one way, then the other, for the same exposure.

\section{Letters and Notes}

\section{Panophthalmitis After Cataract Operations}

Dr. J. T. MaClachlan (Glasgow) writes: I am of opinion that if $\subseteq$ Lis'er's antiseptic technique is employed in operations on the eye, $\vec{F}$ panophthalmitis and other complications would not arise. $\mathrm{Dr}$. William MacKenzie, the famous Glasgow oculist, devised over $100 \mathrm{O}$ years ago an excellent antiseptic lotion for diseases of the eye. MacKenzie's lotion consists of : bichloride of mercury $1 \mathrm{gr}$. (65 mg.), chloride of ammonium 6 gr. (400 mg.), coccus cacti (cochineal)

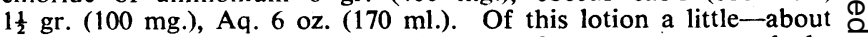
a spoonful-is diluted with equal parts of warm water, and the eye bathed several times daily with a piece of linen or sponge, $\infty$ and the head titlted back and some of the lotion allowed to run into $\overrightarrow{0}$ the eye. If MacKenzie's lotion were used several times daily for one week before operation and for some time after the operation, I $\overrightarrow{\vec{\omega}}$ believe septic complications would not arise. To prevent haemorrhage $\mathscr{\sigma}^{\circ}$ in the eye after operations for cataract, if the blood pressure is high $\bar{\partial}$ it can be safely reduced to 120 by giving "liq. trinitrini " 1 or 23 min. $(0.06$ or $0.12 \mathrm{ml}$.) along with some spirits of sweet nitre some time before and after the operation.

\section{Definition of Health}

Mr. Patrick Slater writes: The Oxford English Dictionary is authorizes the use of the word "health" to indicate a variable i state. I have never known anyone take etymological exception to the question. "How is your health?" or to qualifying " health" 을 with such adjectives as excellent, good, indifferent, or poor. Indeed, $A$ until some qualifying words are added, an individual's health remains $c$ undefined. Moreover the World Health Organization, the Ministry of Health, the United States Public Health Service, etc., do not limit their terms of reference to states of complete physical, mental, and social well-being. If as a result of the decision of the World Health Organization the word " health" is henceforth to be applied $\vec{\varphi}$ only to such a state, may I ask: Has the word any connotation $¥$ whatever? What comprehensive term, if any, applies universally to all the observable conditions which approximate to or deviate from this perfect state? How can their decision be enforced?

\section{Notes from Russia}

Dr. W. P. ForRest, chief medical officer of the U.N.R.R.A. $\stackrel{\circ}{\mathbb{D}}$ Mission to the Soviet Ukraine, sends us the following medical $\unrhd$ news from Kiev: The late Prof. Alexander Bogomoletz, whose $\overrightarrow{\overrightarrow{0}}$ work on the antireticular cytoxic serum was outlined in this Journal $(1943,2,203)$, has been succeeded as President of the Ukrainian Academy of Sciences by Alexander B. Palladin, a member of the Ukrainian, Byelorussian, and U.S.S.R. Academies of Sciences and of the All Union Academy of Medical Sciences. Palladin has written over 150 scientific papers, and has founded many institutes and societies. His latest work is on vitamins and the biochemistry of muscular action. The son of Prof. Bogomoletz is now director $\bar{\sigma}$ of the famous Kiev Institute of Pathological Physiology. Academician V. P. Filatov is once more installed in the partially reconstructed Filatov Ophthalmological Institute. He has arranged to do several articles in English on tissue therapy in ophthalmology and leprosy. There is an enormous demand here for literature to $ᄋ$ replace the medical libraries, which were almost completely destroyed by the invaders. Not only are old journals and books required to $\widetilde{N}$ replace those lost, but recent and current books and journals are $D$ more than welcome. They can be sent $\mathrm{c} / \mathrm{o}$ the U.N.R.R.A. Mission to the Ukraine, or to I. F. Kononenko, People's Minister of Health, Kiev, Ukrainian S.S.R.

\section{Corrections}

In the article headed "Classifying Caúses of Death" (Journal, $\widetilde{O}$ Dec. 21, 1946, p. 957) the chairman of the Medical Advisory Committee, Sir Ernest Rock Carling, should have been described as formerly Dean of Westminster Hospital Medical School.

A misprint occurred in the article by Dr. A. J. Suchecki on "Allergic Reactions to Penicillin" (Journal, Dec. 21, 1946, p. 938). Under the subheading "Review of the 'Literature" the word $O$ " included," in the second line from the end, should read " excluded."

All communications with regard to editorial business should be addressed to THE $\sigma$ EDITOR, BRITISH MEDICA JOURNAL B M A HOUSE TAVISTOCK, SOUARE, EDTR, BRIS TELPHONE: EUSTON 2111. TEIEGRAMS: Aitiology, Westcent, London ORIGINAL ARTICLES AND LETTERS forwarded for publication are understood to be offered to the British Medical Journal alone. publication are understood to be offed to the Bich Medical Journal alone. Authors dist Manager. B.M A. House, Tavis ock Square to the Advertisement Manager. B.M. House Tavistock Square, London, W.C.1 (hours 9 a.m. to 5 p.m.) B.M.A. House. Tavistock Square, London, W.C.1 (hours 9 a.m. to 5 p.m.) TELEPHONR: :EUSTON 2111. TELEGRAMS: Articulate, Westcent, London. Associat SUBCRIPTINS should be sent to the SECRETARY of the Associa

B.M.A. SCOTtish OfFICE: 7, Drumsheugh Gardens, Edinburgh 